\section{Examining the effect of individual innovation level of students of sports sciences faculty on digital literacy with structural equation model}

\section{Spor bilimleri fakültesi öğrencilerinin bireysel yenilikçilik düzeyinin dijital okuryazarlığa etkisinin yapısal eşitlik modeli ile incelenmesi}

\begin{abstract}
The aim of this study is to determine the effect of individual innovation level of students of the Faculty of Sport Sciences on digital literacy. The study group of the research; It consists of 205 participants who continue their education in a higher education institution in Ankara that provides undergraduate sports education in the 2019-2020 academic year. Data collection tools; it is "Individual Innovation Scale" and "Digital Literacy Scale". In the research, a theoretical model was created and tested. In the analysis of the data; structural equation model, descriptive statistics and Independent Samples T-test were used. When the analysis results are examined; It can be stated that the participants have a questioning innovation identity. However, it can be said that they have an above average digital literacy skill. Considering the gender variable, the level of digital literacy of male participants was found to be significantly higher than that of female participants. In addition, research results show that individual innovativeness explains digital literacy by $37 \%$. Therefore, it can be stated that individual innovation significantly predicts digital literacy.
\end{abstract}

\section{Özet}

Bu çalışmanın amacı, Spor Bilimleri Fakültesi öğrencilerinin bireysel yenilikçilik düzeyinin dijital okuryazarllğa etkisinin belirlenmesidir. Araştırmanın çalışma grubunu; 2019-2020 eğitim-öğretim y1lında Ankara'da bulunan ve lisans düzeyinde spor eğitimi veren bir yükseköğretim kurumunda eğitimlerine devam eden 205 katılımcı oluşturmaktadır. Veri toplama araçları; "Bireysel Yenilikçilik Ölçeği" ve "Dijital Okuryazarlık Ölçeği" dir. Araştırmada teorik bir model oluşturulmuş ve test edilmiştir. Verilerin analizinde; yapısal eşitlik modeli, betimsel istatistikler ve Bağımsız Örneklemler T-testi kullanılmıştır. Analiz sonuçları incelendiğinde; katılımcıların sorgulayıcı bir yenilikçilik kimliğine sahip olduğu ifade edilebilir. Bununla beraber, ortalamanın üzerinde bir dijital okuryazarlık becerisine de sahip oldukları söylenebilir. Cinsiyet değişkeni ele alındığında, erkek katılımcıların dijital okuryazarlık düzeyinin kadın katılımcılara göre anlamlı düzeyde yüksek olduğu belirlenmiştir. Ayrıca araştırma sonuçları, bireysel yenilikçiliğin dijital okuryazarlığı $\% 37$ oranında açıkladığını

1 Araş. Gör. Dr., Karamanoğlu Mehmetbey Üniversitesi, Beden Eğitimi ve Spor Yüksekokulu, nuriberkgungor@gmail.com (iD) Orcid ID: 0000-0002-6579-9146 
Güngör, N. B., \& Kurtipek, S. (2020). Spor bilimleri fakültesi öğrencilerinin bireysel yenilikçilik düzeyinin dijital okuryazarlığa etkisinin yapısal eşitlik modeli ile incelenmesi. Journal of Human Sciences, 17(2), 756-767. doi:10.14687/jhs.v17i2.6021

Keywords: Individual innovation; Digital göstermektedir. Dolayısıyla, bireysel literacy; Sports sciences; Structural equality.

(Extended English summary is at the end of $\underline{\text { this document) }}$ yenilikçiliğin dijital okuryazarlığı önemli düzeyde yordadığı belirtilebilir.

Anahtar Kelimeler: Bireysel yenilikçilik; Dijital okuryazarlık; Spor bilimleri; Yapısal eşitlik.

\section{Giriş}

Günümüzde teknolojinin hızla gelişmesi, kısa bir zaman diliminde alışkanlıklarımızın farklılaşması ve yeni ürünlerin kullanım kolaylığı sağlaması yeniliklere olan bakış açısını da etkilemektedir. Rogers, Medina, Rivera \& Widey (2005) yenilĭgi tanımlarken, birey veya toplum tarafından yeni bir uygulama veya nesnenin var olmasının gerekliliğini ifade etmiştir. Yenilikçilik ise, kişinin herhangi bir yeniliği diğer kişilere göre daha çabuk kabullenmesi olarak da ifade edilebilir (Rogers \& Wallace, 2011). Her bireyin yenilikçilik ile ilgili düşüncesi farklı olabilir. Bir birey yenilik içeren bir olguyu daha hızlı bir şekilde benimserken, farklı bir kişi daha geç benimseyebilir ve yenilikleri kabullenme sürecinde risk alma potansiyelleri farklılık gösterebilir (Demirel \& Seçkin, 2008).

Yenilikçi kişilerin en önemli özelliği yeniliği takip etme eğilimidir. Bu eğilim mevcudun dışında oluşanları arama isteği olarak da belirtilebilir. Yeniliklerin kabullenilmesinde ve kalıcılığının sağlanmasında önemli bir role sahiptir. Yeniliği takip etme eğilimine sahip olan bireyler bilgi edinirken doğrudan yenilikleri deneyerek hedeflerine ulaşırlar (Hirschman, 1980). Problemin ortaya konması ve yeni fikirlerin ifade edilmesi yenilikçi davranışı betimler. Daha sonra yenilikçi birey düşüncesini güçlendirmek ister ve bir destek arar. Nihayetinde kişi yeniliği somut olarak uygulamaya koyar (Çakın, 2019). Yenilikçi bir bakış açısına sahip olan kişi problemler hakkında düşünüp, onlara çözüm sağlamayı hedefler. Bununla beraber, yeni ve faklı ilişkiler kurmaya önem vererek mevcut durumların arkasında yer alan görünmeyeni arar (Çekmecelioğlu, 2002). Bireylerin eğitim seviyesinin yüksek olması, alanlarında tecrübe sahibi olmaları, yaratıcı düşünme becerilerini kullanabilmeleri ve motivasyon sahibi olmaları da bireysel yenilikçilik düzeyine katkı sağlayan unsurlardir.

Bireylerin yenilikçi profillerinin görülebileceği alanlardan biri de dijital dünyadır. Dijital dünyanın araç ve gereçleri her geçen gün gelişim göstererek yenilenmektedirler. Bugün yeni olarak nitelendirilebilen bir teknoloji yarın eski olarak karşımıza çıkabilmektedir. Bu gelişime ayak uydurabilmek bireyler için önem taşımaktadır. Çünkü herhangi bir buluşun bireyler tarafindan kabullenilmesi toplumda yer edinebilmesi adına önem taşımaktadır. Sonrasında ise her bireyin kullanması gereken bir gereklilik olarak karşımıza çıkmaktadır.

Dijital okuryazarlık ise, yenilikçi dijital materyallerin ve bunlarla ilişkili paydaşlarının kullanımına yatkınlık anlamına gelmektedir. Bu materyalleri kullanabilme becerisi aynı zamanda üretim için etkin bir ortam sağlar. Bununla beraber, ağ tabanlı suçlardan olan kimlik avı ve bilgisayar korsanlığı gibi durumlara karşıda bir farkındalık yaratır. (Deye, 2015). Ayrıca, dijital kaynaklara ulaşarak ve onları yöneterek yeni ürünlere ulaşma konusunda öncülük eder (Martin, 2005). Dijital okuryazar bireyler doğru bilgiye ulaşabilen, bilgiyi kullanarak sentez becerisine sahip ve dijital ortamlarda bu bilgili sunabilen kişilerdir (Kozan \& Bulut Özek, 2019). Dijital tabanlı öğrenme ortamlarında da bu durum ayrı bir önem taşımaktadır.

Birçok alanda olduğu gibi dijital dönüşüm eğitim alanında da farklılık yaratmaya başlamıştır. Uzaktan eğitim sistemleri, dijital materyallerin hazırlanması, program ara yüzlerinin kullanılabilmesi birer gereklilik haline gelmiştir. Literatür incelendiğinde dijital okuryazarlık ile ilgili farklı çalışmaların olduğu görülmektedir (Gürtekin, 2019; Greene, Seung \& Copeland, 2014; Horne, 2007; Meyers, Ericson \& Small, 2013; Özerbaş \& Kuralbayeva; 2018; Yontar; 2019). Ancak, bireysel yenilikçiliğin dijital okuryazarlık üzerine yordayıcı etkisini konu alan bir çalışmaya rastlanmamıştır. 
Güngör, N. B., \& Kurtipek, S. (2020). Spor bilimleri fakültesi öğrencilerinin bireysel yenilikçilik düzeyinin dijital okuryazarlığa etkisinin yapısal eşitlik modeli ile incelenmesi. Journal of Human Sciences, 17(2), 756-767. doi:10.14687/jhs.v17i2.6021

Dolayısıyla bu çalışma gerek literatüre katkı sağlaması gerekse de Spor Bilimleri Fakültesi öğrencilerinin dijital okuryazarlık düzeylerinin belirlenebilmesi bakımından önem taşımaktadır. Bu noktadan hareketle araştırmada, Spor Bilimleri Fakültesi’nde öğrenim görmekte olan bireylerin bireysel yenilikçilik ile dijital okuryazarlık düzeylerini belirleyerek, bireysel yenilikçiliğin dijital okuryazarlı̆̆1 yordama gücünü yapısal eşitlik modeli ile ortaya koymak amaçlanmıştır.

\subsection{Araştırma Modeli ve Hipotezler}

\section{Yöntem}

Araştırmada ilişkisel tarama modeli kullanılmıştır. Bu model; iki ya da daha fazla değişken arasındaki ilişkiyi belirlemek ve neden-sonuç ile ilgili ipuçları elde edebilmek amacı ile kullanılmaktadır (Karasar, 2017). Literatür incelemesi sonucunda araştırmanın modeli, mevcut değişkenler temel alınarak kurulmuştur. Teorik modelin testi yapısal eşitlik modeli kullanılarak test edilmiştir. Yapısal eşitlik, regresyon ve faktör analizinin birleşimi olup gizil ve gözlenen değişkenler tarafından temsil edilen teorik bir yapıdır (Byrne, 2010). Literatür taraması sonucunda oluşturulan modele ait hipotezler aşağıda verilmiştir.

$\mathbf{H}_{1}$ : Değişime direnç (DD), dijital okuryazarlığı (DO) pozitif yönde etkiler.

$\mathbf{H}_{2}$ : Fikir önderliği (FÖ), dijital okuryazarlığı (DO) pozitif yönde etkiler.

$\mathbf{H}_{3}$ : Deneyime açıklık (DA), dijital okuryazarlığı (DO) pozitif yönde etkiler.

$\mathbf{H}_{4}$ : Risk alma (RA), dijital okuryazarllğı (DO) pozitif yönde etkiler.

\section{2. Çalışma Grubu}

Araştırmanın çalışma grubunu; 2019-2020 eğitim-öğretim yılında Ankara'da bulunan ve lisans düzeyinde spor eğitimi veren bir yükseköğretim kurumunda eğitimlerine devam eden 205 katılımcı oluşturmaktadır. Buna ek olarak araştırmada, amaçlı örnekleme yöntemlerinden kolay ulaşılabilir örnekleme tekniği kullanılmıştır (Büyüköztürk, Kılıç Çakmak, Akgün, Karadeniz \& Demirel, 2009). Katılımcıların 89'u (\%43.4) kadın, 116's1 (\%56.6) erkek öğrencilerden oluşurken; 56's1 (\%27.3) birinci, 49’u (\%23.9) ikinci, 51'i (\%24.9) üçüncü ve 49'u (\%23.9) dördüncü sinıfta eğitim görmektedir. Bununla beraber; 74’ü (\%36.1) lisanslı olarak herhangi bir spor dalı ile ilgilenmekteyken, 131’i (\%63.9) bu kategoriye girmemektedir. Katılımcıları yaş ortalaması ise 21.69 2.62 olarak belirlenmiştir.

\subsection{Veri Toplama Araci}

Araştırmada kişisel bilgi formunun yanı sıra, Bireysel Yenilikçilik ve Dijital Okuryazarlık Ölçekleri kullanılmıştır.

Bireysel Yenilikęilike Ölçeği (BYÖ); Hurt, Joseph \& Cook'un (1977) geliştirilip, Kılıçer \& Odabaş1 (2010) tarafindan Türkçe'ye uyarlanmıştır. Ölçek 5'li likert bir yapıda olup, toplamda 4 alt boyut ve 20 maddeden oluşmaktadır. Bu alt boyutlar ise; değişime direnç, fikir önderliği, deneyime açıklık ve risk alma olarak isimlendirilmiştir. Yenilikçilik puanı ölçekte yer alan pozitif maddelerden alınan toplam puandan negatif maddelerden elde edilen toplam puanın çıkarılarak 42 puan eklenmesi ile hesaplanmaktadır. Ölçekten toplamda en düşük 14, en yüksek ise 94 puan alınabilmektedir. Hesaplanan puanlara göre katılımcıların bireysel yenilikleri ketegorize edilebilmektedir. Hesaplanan puan 80'in üzerinde ise "Yenilikçi", 69 ve 80 aralığında ise "Öncü", 57 ve 68 aralığında ise "Sorgulayıcı", 46 ve 56 puan aralığında ise "Kuşkucu", 46 puan altında ise "Gelenekçi” olarak ifade edilmektedir. Ayrıca; 68 üstü puan alan bireyler oldukça yenilikçi olarak atfedilirken, 64 puanın altındaki bireylerde yenilikçilikte düşük olarak yorumlanmaktadır. Ölçeğin orijinal formu incelendiğinde tamamına ve alt boyutlara ilişkin güvenirlik katsayısı sırasıyla; .82, .81, .73, .77, .62 olarak görülmektedir (Kılıçer \& Odabaşı, 2010). Veri setinden elde edilen güvenirlik katsayıları ise sırasıyla; $.85, .81, .79, .74$ ve .64 şeklinde hesaplanmıştır. 
Güngör, N. B., \& Kurtipek, S. (2020). Spor bilimleri fakültesi öğrencilerinin bireysel yenilikçilik düzeyinin dijital okuryazarlığa etkisinin yapısal eşitlik modeli ile incelenmesi. Journal of Human Sciences, 17(2), 756-767. doi:10.14687/jhs.v17i2.6021

Dijital Okuryazarlı Ölçĕgi (DOÖ); Ng (2012) tarafindan geliştirilip, Üstündăg, Güneş \& Bahçıvan (2017) tarafından Türkçe'ye kazandırılmıştır. 5’li likert bir yapıda olan ölçekte toplamda 10 madde yer almaktadır. Ölçekten alınan puan yükseldikçe dijital okuryazarlık seviyesi de artmaktadır. Üstündağ, Güneş \& Bahçıvan'ın (2017) çalışması incelendiğinde ölçeğin iç tutarlık katsa1yısı .86 olarak görülmektedir. Araştırma kapsamında kullanılan veri setinden elde edilen iç tutarlık katsayısı ise .87'dir.

\section{Araştırma kapsammda kullanılan ölçme araçlarnm doğrulayncı faktör analizi sonuçlar}

Bireysel Yenilikçilik ve Dijital Okuryazarlık Ölçeklerinin yapı geçerliğini test edebilmek amacıyla doğrulayıcı faktör analizi uygulanmıştır. Uyum iyiliği değerleri ile ilgili, Amos 22 paket programının önerileri doğrultusunda Bireysel Yenilikçilik Ölçeğinin 2 ve 3 numaraları maddeleri arasında kovaryans ataması gerçekleştirilmiştir. Elde edilen değerler incelendiğinde, Bireysel Yenilikçilik $\left(\mathrm{x}^{2} / \mathrm{sd}=1.81, \mathrm{RMSEA}=.06, \mathrm{PGFI}=.70, \mathrm{PNFI}=.71, \mathrm{GFI}=.88, \mathrm{AGFI}=.85, \mathrm{CFI}=\right.$ .90) ve Dijital Okuryazarlı Ölçekleri için $\left(\mathrm{x}^{2} / \mathrm{sd}=1.62\right.$, RMSEA $=.05$, PGFI $=.95$, PNFI $=.72$, GFI $=.89, \mathrm{AGFI}=.86, \mathrm{CFI}=.97)$ uyum iyiliği kriterlerini sağladığ 1 ifade edilebilir. Elde edilen nihai uyum indeks değerleri; Bireysel Yenilikçilik Ölçeğinin 4 faktörlü, Dijital Okuryazarlık Ölçeğinin ise tek faktörlü yapısının doğrulandığını göstermektedir (Schermelleh-Engel \& Moosbrugger, 2003; Kline, 2005; Tabachnick \& Fidell, 2007; Meydan \& Şeşen, 2011).

\subsection{Verilerin Analizi}

Verilerin analizi sürecinde öncelikle veri setinden uç değere sahip 8 ölçek formu çıkarılmıştır. Daha sonra dağılımın normal olup olmadığını belirlemek amacı ile Shapiro-Wilk testi kullanılmıştır. Shapiro-Wilk testi anlamlılık sonucu araştırmada kullanılan ölçekler için p $>.05$ bulunmuştur. $\mathrm{Bu}$ sonuçla beraber verilerin normal dağılım koşullarını sağladığı sonucuna ulaşılmıştır (Tabachnick \& Fidell, 2013). Verilerin faktör analizine uygunluğu ise Kaiser-Mayer-Olkin (KMO) katsayıs1 ve Bartlett testi gerçekleştirilerek belirlenmiştir. Analiz sonuçlarına göre; Bireysel Yenilikçilik Ölçeği için .83 ve Dijital Okuryazarlık Ölçeği için .90 KMO uygunluk katsayısı belirlenmiştir. Buna ek olarak, Barlett testi sonucu da araştırma kapsamında kullanılan ölçekler için anlamlı olarak belirlenmiştir $(\mathrm{p}<.001)$. Dolayısıyla, bu değerler verilerin faktör analizine uygunluğunu göstermektedir (Leech, Barlett \& Morgan, 2005; Şeker, Deniz \& Görgen, 2004). Ölçeklerin faktör analizine uygunluğunun tespiti ile birlikte araştırmada oluşturulan teorik model, bir yapisal eşitlik modeli kurularak test edilmiştir. Yapısal eşitlik modellerinin temel amacı, kuramsal olarak oluşturulan teorik bir modelin elde edilen verilerle istatistiksel olarak test edilmesi ve teori ile araştırma bulgularının ne kadar uyuştuğunun belirlenmesidir (Hair, Black, Babin \& Anderson, 1998). Bununla beraber, katılımcıların ölçeklerden aldıkları ortalama puanların cinsiyet ve lisanslı sporculuk durumu değişkenlerine göre karşılaştırılması amacıyla Bağımsız Örneklemler T-testi kullanılmıştır. Çalışmada analizler; AMOS 22.0, SPSS 22.0 paket programları kullanılarak gerçekleştirilmiştir.

\section{Bulgular}

Tablo 1. Katılımcıların Bireysel Yenilikçilik Ölçeği ve alt boyutları ile Dijital Okuryazarlık Ölçeğinden aldıkları ortalama puanlar

\begin{tabular}{|c|c|c|c|c|c|}
\hline Ölçekler & $\mathrm{N}$ & Min & Max & $\overline{\mathrm{X}}$ & $S$ \\
\hline Değişime Direnç & 205 & 1.88 & 5.00 & 3.30 & .65 \\
\hline Fikir Önderliği & 205 & 1.60 & 5.00 & 3.87 & .62 \\
\hline Deneyime Açılklk & 205 & 1.80 & 5.00 & 4.05 & .55 \\
\hline Risk Alma & 205 & 1.50 & 5.00 & 3.59 & .72 \\
\hline B.Y.Ö. Toplam & 205 & 34.00 & 82.00 & 62.41 & 6.80 \\
\hline D.O.Ö. Toplam & 205 & 1.40 & 5.00 & 3.54 & .64 \\
\hline
\end{tabular}


Güngör, N. B., \& Kurtipek, S. (2020). Spor bilimleri fakültesi öğrencilerinin bireysel yenilikçilik düzeyinin dijital okuryazarlığa etkisinin yapısal eşitlik modeli ile incelenmesi. Journal of Human Sciences, 17(2), 756-767. doi:10.14687/jhs.v17i2.6021

Katılımcıların Bireysel Yenilikçilik Ölçeğinden aldıkları ortalama puan ( $\overline{\mathrm{X}}=62.41)$, değişime direnç alt boyutundan $(\overline{\mathrm{X}}=3.30)$, fikir önderliği alt boyutundan $(\overline{\mathrm{X}}=3.87)$, deneyime açıklık alt boyutundan $(\overline{\mathrm{x}}=4.05)$ ve risk alma alt boyutundan $(\overline{\mathrm{x}}=3.59)$ 'dur. Bu noktadan hareketle kat1limcilarin sorgulayıc1 $(\overline{\mathrm{X}}=62.41)$, kategorisinde yer aldıkları ifade edilebilir. Bununla beraber, Dijital Okuryazarlık Ölçeğinden alınan ortalama puan $(\overline{\mathrm{X}}=3.54)$ olarak tespit edilmiştir.

Tablo 2. Katılımcıların ölçeklerden aldıkları puan ortalamalarının cinsiyet değişkenine göre Bağımsız Örneklemler T-testi sonuçları

\begin{tabular}{|c|c|c|c|c|c|c|c|}
\hline & Cinsiyet & $\mathrm{N}$ & $\bar{x}$ & Ss & $\mathrm{sd}$ & $\mathrm{t}$ & $\mathrm{p}$ \\
\hline \multirow[t]{2}{*}{ D.D.A.B. } & Kadın & 89 & 3.32 & .66 & \multirow{2}{*}{203} & \multirow[t]{2}{*}{.30} & \multirow[t]{2}{*}{.95} \\
\hline & Erkek & 116 & 3.30 & .65 & & & \\
\hline \multirow[t]{2}{*}{ F.Ö.A.B. } & Kadın & 89 & 3.78 & .66 & \multirow[t]{2}{*}{203} & \multirow[t]{2}{*}{-1.88} & \multirow[t]{2}{*}{.32} \\
\hline & Erkek & 116 & 3.94 & .57 & & & \\
\hline \multirow[t]{2}{*}{ D.A.A.B. } & Kadın & 89 & 4.05 & .56 & \multirow[t]{2}{*}{203} & \multirow[t]{2}{*}{-.17} & \multirow[t]{2}{*}{.63} \\
\hline & Erkek & 116 & 4.06 & .54 & & & \\
\hline \multirow[t]{2}{*}{ R.A.A.B. } & Kadın & 89 & 3.53 & .75 & \multirow[t]{2}{*}{203} & \multirow[t]{2}{*}{-1.01} & \multirow[t]{2}{*}{.78} \\
\hline & Erkek & 116 & 3.64 & .70 & & & \\
\hline \multirow{2}{*}{$\begin{array}{l}\text { B.Y.Ö. } \\
\text { Toplam }\end{array}$} & Kadın & 89 & 61.6 & 7.62 & \multirow[t]{2}{*}{203} & \multirow[t]{2}{*}{1.37} & \multirow[t]{2}{*}{.28} \\
\hline & Erkek & 116 & 62.9 & 6.06 & & & \\
\hline D.O.Ö. & Kadın & 89 & 3.42 & .62 & \multirow{2}{*}{203} & \multirow[t]{2}{*}{-2.20} & \multirow[t]{2}{*}{.02} \\
\hline Toplam & Erkek & 116 & 3.62 & .66 & & & \\
\hline
\end{tabular}

Kadın katılımcıların Bireysel Yenilikçilik Ölçeğinden aldıkları ortalama puan $(\overline{\mathbf{X}}=61.6)$, erkek katılımcıların ( $\overline{\mathrm{X}}=62.9)^{\prime}$ 'dur. Analiz sonuçları, katılımcıların bireysel yenilikçilik düzeyinin cinsiyet değişkenine göre anlamlı bir farklılık ifade etmediğini göstermektedir, $\mathrm{t}_{5}(203)=1.37, \mathrm{p}>.05$. Buna ek olarak, katılımcıların ölçeğin alt boyutlarından aldıkları ortalama puanlar dikkate alındığında değişime direnç, fikir önderliği, deneyime açıklık ve risk alma ile cinsiyet arasında istatistiksel olarak anlamlı bir farklılık olmadığ belirlenmiştir, $\mathrm{t}_{1}(203)=.30, \mathrm{p}>.05 ; \mathrm{t}_{2}(203)=-1.88, \mathrm{p}>.05 ; \mathrm{t}_{3}(203)=-.17$, $\mathrm{p}>.05 ; \mathrm{t}_{4}(203)=-1.01, \mathrm{p}>.05$. Ayrica, dijital okuryazarlık ile cinsiyet arasinda erkek katılımciların lehine istatistiksel olarak anlamlı bir farklılık tespit edilmiştir, $\mathrm{t}_{6}(203)=-2.20, \mathrm{p}<.05$.

Tablo 3. Katılımcıların ölçeklerden aldıkları puan ortalamalarının lisanslı sporculuk durumu değişkenine göre T-testi sonuçları

\begin{tabular}{|c|c|c|c|c|c|c|c|}
\hline & L. Sporcu & $\mathrm{N}$ & $\bar{x}$ & Ss & sd & $\mathrm{t}$ & $\mathrm{p}$ \\
\hline \multirow[t]{2}{*}{ D.D.A.B. } & Evet & 74 & 3.33 & .70 & \multirow{2}{*}{203} & \multirow[t]{2}{*}{.35} & \multirow[t]{2}{*}{.72} \\
\hline & Hayır & 131 & 3.29 & .63 & & & \\
\hline \multirow[t]{2}{*}{ F.Ö.A.B. } & Evet & 74 & 4.00 & .67 & \multirow[t]{2}{*}{203} & \multirow[t]{2}{*}{2.14} & \multirow[t]{2}{*}{.03} \\
\hline & Hayır & 131 & 3.80 & .58 & & & \\
\hline \multirow[t]{2}{*}{ D.A.A.B. } & Evet & 74 & 4.10 & .58 & \multirow[t]{2}{*}{203} & \multirow[t]{2}{*}{.78} & \multirow[t]{2}{*}{.43} \\
\hline & Hayır & 131 & 4.03 & .53 & & & \\
\hline \multirow[t]{2}{*}{ R.A.A.B. } & Evet & 74 & 3.58 & .76 & \multirow[t]{2}{*}{203} & \multirow[t]{2}{*}{-.14} & \multirow[t]{2}{*}{.88} \\
\hline & Hayır & 131 & 3.60 & .70 & & & \\
\hline \multirow[t]{2}{*}{ B.Y.Ö. } & Evet & 74 & 63.04 & 6.89 & \multirow[t]{2}{*}{203} & \multirow[t]{2}{*}{.98} & \multirow[t]{2}{*}{.33} \\
\hline & Hayır & 131 & 62.06 & 6.74 & & & \\
\hline \multirow[t]{2}{*}{ D.O.Ö. } & Evet & 74 & 3.58 & .68 & \multirow{2}{*}{203} & \multirow[t]{2}{*}{.63} & \multirow[t]{2}{*}{.53} \\
\hline & Hayır & 131 & 3.52 & .62 & & & \\
\hline
\end{tabular}

Katılımcıların Bireysel Yenilikçilik Ölçeği ve alt boyutlarından aldıkları puan ortalamaları lisanslı sporculuk durumu değişkenine göre karşılaştırıldığında yalnızca fikir önderliği alt boyutunda lisanslı sporcuların lehine istatistiksel olarak anlamlı bir farklllik tespit edilmiştir, $\mathrm{t}_{2}(203)=2.14$, $\mathrm{p}<.05$. Bununla beraber, dijital okuryazarlık ile lisanslı sporculuk durumu arasinda anlamlı bir farklı1ık olmadığı belirlenmiştir, $\mathrm{t}_{6}(203)=.63, \mathrm{p}>.05$. 
Güngör, N. B., \& Kurtipek, S. (2020). Spor bilimleri fakültesi öğrencilerinin bireysel yenilikçilik düzeyinin dijital okuryazarlığa etkisinin yapısal eşitlik modeli ile incelenmesi. Journal of Human Sciences, 17(2), 756-767. doi:10.14687/jhs.v17i2.6021

\section{Dijital Okuryazarlğgn Path (Yol) analiæi ile incelenmesine yönelik bulgular}

Araştırma kapsamında bir yapısal eşitlik modeli test edilmeden önce "dijital okuryazarlık" ile "bireysel yenilikçilik" arasındakileri test edebilmek amacıyla korelasyon analizi uygulanmıştır. Değişken arasındaki ilişkiler Pearson Momentler Çarpımı Korelasyon Analizi yöntemi ile belirlenmiştir. Tablo 4'de analiz sonuçları verilmiştir.

Tablo 4. Değişkenlerarası ilişkinin Pearson Momentler Çarpımı Korelasyonu ile incelenmesi

\begin{tabular}{|c|c|c|c|c|c|}
\hline Değişken & $\begin{array}{l}\text { Değişime } \\
\text { Direnç }\end{array}$ & $\begin{array}{c}\text { Fikir } \\
\text { Önderliği }\end{array}$ & $\begin{array}{c}\text { Deneyime } \\
\text { Açılkık }\end{array}$ & $\begin{array}{l}\text { Risk } \\
\text { Alma }\end{array}$ & $\begin{array}{c}\text { Dijital } \\
\text { Okuryazarlık }\end{array}$ \\
\hline Değişime Direnç & 1 & & & & \\
\hline Fikir Önderliği & $.20^{* *}$ & 1 & & & \\
\hline Deneyime Açıklık & $.36^{* *}$ & $.67^{* *}$ & 1 & & \\
\hline Risk Alma & $.11^{* *}$ & $.33^{* *}$ & $.39^{* *}$ & 1 & \\
\hline Dijital Okuryazarlık & $.12^{* *}$ & $.44^{* *}$ & $.35^{* *}$ & $.33^{* *}$ & 1 \\
\hline
\end{tabular}
**p $<.01$

Tablo 4 incelendiğinde, katılımcıların dijital okuryazarlık ile değişime direnç $\left(r_{1}=.12, p<.01\right)$ puanları arasında pozitif yönlü ve düşük düzeyde bir ilişki olduğu görülmektedir. Dijital okuryazarlık ile fikir önderliğ $\left(\mathrm{r}_{2}=.44, \mathrm{p}<.01\right)$, deneyime açıllı $\left(\mathrm{r}_{3}=.35, \mathrm{p}<.01\right)$ ve risk alma $\left(\mathrm{r}_{4}=.33\right.$, $\mathrm{p}<.01$ ) arasında ise orta düzeyde ve pozitif yönlü bir ilişki belirlenmiştir (Büyüköztürk, 2014). Araştırmanın değişkenleri arasındaki ilişkilerin ortaya koyulmasından sonra bireysel yenilikçiliğin dijital okuryazarlık üzerindeki yordayıcı etkisi yol analizi test edilmiştir.

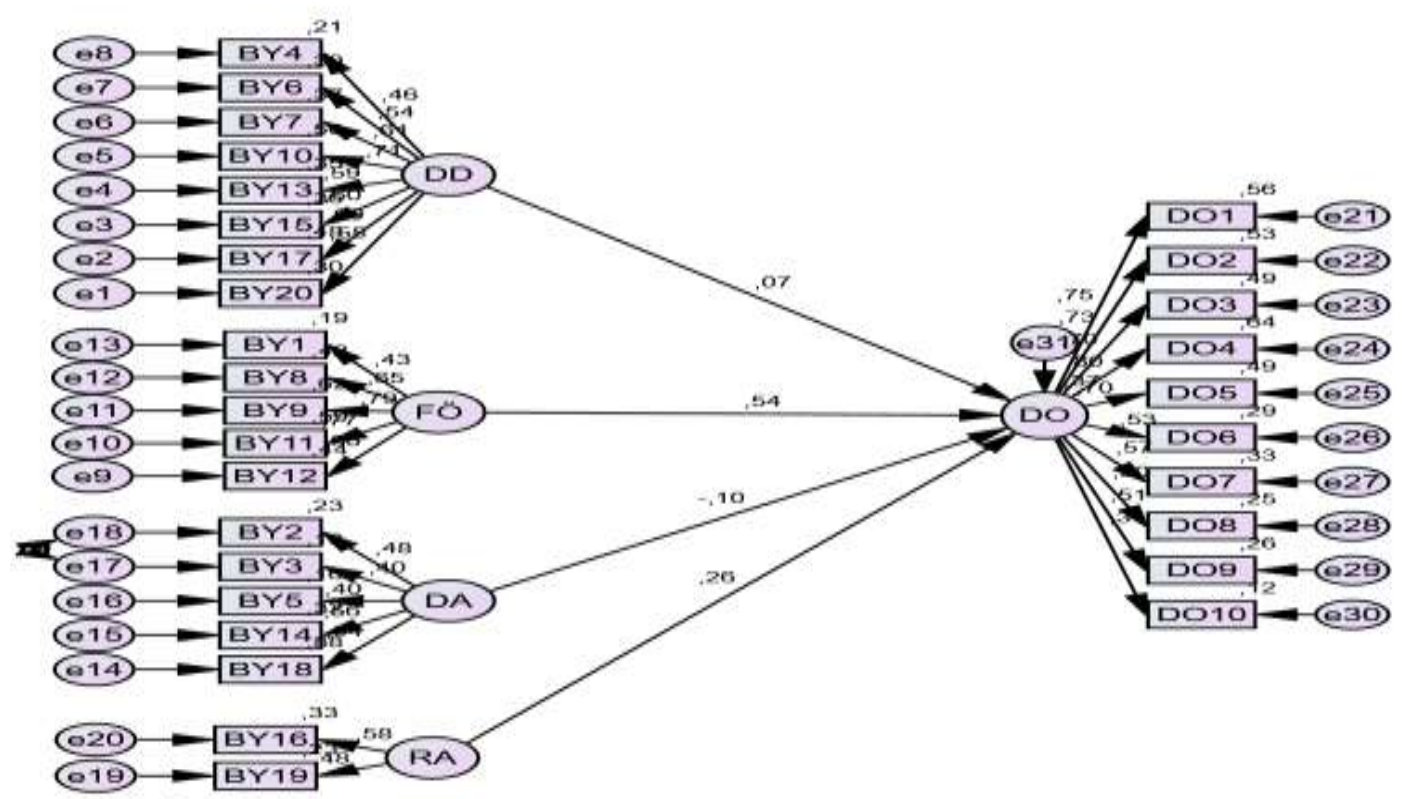

Şekil 1. Yapısal eşitlik modeli 
Güngör, N. B., \& Kurtipek, S. (2020). Spor bilimleri fakültesi öğrencilerinin bireysel yenilikçilik düzeyinin dijital okuryazarlığa etkisinin yapısal eşitlik modeli ile incelenmesi. Journal of Human Sciences, 17(2), 756-767. doi:10.14687/jhs.v17i2.6021

Şekil 1'de görülmekte olan modelin gerekli uyum iyiliği kriterlerini sağladığı ifade edilebilir $\left(\mathrm{x}^{2} / \mathrm{sd}=2.26\right.$, RMSEA $=.06, \mathrm{PGFI}=.88, \mathrm{PNFI}=.86, \mathrm{GFI}=.98, \mathrm{AGFI}=.93$, CFI $\left.=.96\right)$. Modele ilişkin uyum iyiliği indeksi değerleri incelendikten sonra modelde yer alan yollar ve modele ilişkin parametre tahminleri incelenmiştir. Oluşturulan modele göre değişkenler arasındaki standardize edilmiş $\beta$ katsayıları, standart hata, kritik oran, $\mathrm{p}$ ve $\mathrm{R}^{2}$ değerleri Tablo 5'de gösterilmiştir.

Tablo 5. Yapısal eşitlik modeli sonuçları

\begin{tabular}{|c|c|c|c|c|c|c|}
\hline \multicolumn{2}{|c|}{ Değişkenler } & Standardize $\beta$ & $\begin{array}{c}\text { Standart } \\
\text { Hata }\end{array}$ & $\begin{array}{l}\text { Kritik } \\
\text { Oran }\end{array}$ & $\mathrm{p}$ & $\mathrm{R}^{2}$ \\
\hline Değişime Direnç & \multirow{4}{*}{ Dijital Okuryazarlık } & .07 & .10 & .92 & .35 & \multirow{4}{*}{.37} \\
\hline Fikir Önderliği & & .54 & .10 & 5.92 & $* * *$ & \\
\hline \multirow{2}{*}{$\begin{array}{c}\text { Deneyime Açılklk } \\
\text { Risk Alma }\end{array}$} & & -.10 & .07 & -1.50 & .13 & \\
\hline & & .26 & .16 & 2.38 & .017 & \\
\hline
\end{tabular}

Analiz sonuçları, fikir önderliğinin ve risk almanın dijital okuryazarlıkla olan ilişkisinde istatistiksel olarak anlamlı bir etki tespit edildiğini göstermektedir, $\left(\beta_{2}=.54 ; \mathrm{p}<.05 ; \beta_{4}=.26 ; \mathrm{p}<.05\right)$. Bununla beraber, değişime direnç ve deneyime açılılk ile dijital okuryazarlık arasında istatistiksel olarak anlamlı bir etkinin olmadığ1 belirlenmiştir, $\left(\beta_{1}=.07 ; \mathrm{p}>.05 ; \beta_{3}=-.10 ; \mathrm{p}>.05\right)$. Dolayısıyla araştırmanın 1 ve 3 numaralı hipotezleri reddedilmişken, 2 ve 4 numaralı hipotezleri kabul edilmiştir. Modele ait Squared Multiple Correlations $\left(\mathrm{R}^{2}\right)$ değeri ele alındığında, bireysel yenilikçiliğin dijital okuryazarlı̆̆ın \%37'sini açıkladığı görülmektedir.

\section{Tartişma ve Sonuç}

$\mathrm{Bu}$ araşturmada Spor Bilimleri Fakültesi’nde öğrenim görmekte olan bireylerin bireysel yenilikçilik ile dijital okuryazarlık düzeylerini belirleyerek, bireysel yenilikçiliğin dijital okuryazarlığ1 yordama gücünü yapısal eşitlik modeli ile ortaya koymak amaçlanmıştır. Buna ek olarak, katılımcıların araşturmada yer alan ölçeklerden almış oldukları ortalama puanlar cinsiyet ve lisanslı sporculuk durumu değişkenlerine göre de mevcut durumu betimleyebilmek amacıyla incelenmiştir.

Araştırma sonuçları, katıllımcıların bireysel yenilikçilik düzeyinin ortalamanın üzerinde olduğunu ve "sorgulayıcı" kategorisinde yer aldıklarını göstermektedir. İlgili literatür araştrrma sonuçlarını destekler niteliktedir. Çuhadar, Bülbül \& Ilgaz (2013) üniversite öğrencileri ile gerçekleştirdiği çalışmasında, katılımcıların sorgulayıcı bir yenilikçilik profiline sahip olduklarını ifade etmiştir. Korucu \& Olpak (2015) katılımcıların sorgulayıcı kategorisinde yer aldıklarını belirlemiştir. Benzer şekilde Şahin (2016) öğretmen adayları ile gerçekleştirdiği çalışmasında, katılımcıların sorgulayıcı bir yenilikçilik profiline sahip olduklarını ifade etmiştir. Literatürde benzer sonuçların olduğu farklı çalışmalarda mevcuttur (Demircioğlu, Konokman \& Akay, 2016; Ertuğ \& Kaya, 2017; Güngör, 2019; Kilıçer \& Odabaş1, 2010; Kurtipek \& Güngör, 2019; Yalçın \& Yelken, 2011). Literatürde üniversite öğrencileri ile gerçekleştirilen çalışmalarda sıklıkla katılımcıların sorgulayıc1 kategorisinde yer aldığ1 görülmektedir. Bu sonucun sebebinin katılımcıların; herhangi bir şeyi kabul etmeden önce alternatifleri araştırma yaparak inceledikleri, yenilikleri kabul etme konusunda dikkatli bir tutum sergiledikleri, kısa sürede yenilikleri kabullenmedikleri ve bu konuda risk almayı sevmediklerinden kaynaklandığı ifade edilebilir.

Dijital Okuryazarlık Ölçeğinden alınan toplam puan incelendiğinde, katılımcıların dijital okuryazarlık düzeyinin ortalamanın üzerinde olduğu ifade edilebilir. Onursoy (2018) üniversite öğrencilerinin dijital okuryazarlık düzeyinin ortalamanın üzerinde olduğunu belirlemiştir. Üstündağ, Güneş \& Bahçivan (2017) katılımcıların dijital okuryazarlık becerilerinin genel olarak iyi olduğunu vurgulamıştır. Özerbaş \& Kuralbayeva'nın (2018) da benzer bir sonuca ulaştı̆̆ını ifade etmek mümkündür. Bu noktadan hareketle, araştırma sonuçlarının literatür tarafindan desteklendiği ifade edilebilir. Katılımcıların yaş grubu düşünüldüğünde, dijital materyallere ulaşmalarının kolay olması ve günlük hayatlarında sıklıkla bu materyallerin kullanılmasının bu sonucun ortaya çıkmasında etkili olduğu düşünülmektedir. Katılımcıların ölçekten almış oldukları toplam puan değerlendirildiğinde; 
Güngör, N. B., \& Kurtipek, S. (2020). Spor bilimleri fakültesi öğrencilerinin bireysel yenilikçilik düzeyinin dijital okuryazarlığa etkisinin yapısal eşitlik modeli ile incelenmesi. Journal of Human Sciences, 17(2), 756-767. doi:10.14687/jhs.v17i2.6021

yeni teknolojileri kolayca öğrenebilme, farklı teknolojiler hakkında bilgi düzeylerinin ve kullandıkları teknolojiler ile ilgili karşılaşabilecekleri teknik sorunları çözebilme becerilerine sahip oldukları söylenebilir.

Katllımcıların bireysel yenilikçilik düzeyinin cinsiyete göre farklılaşmadığı sonucuna ulaşılmıştır. Safa (2019) çalışmasında, katılımcıların bireysel yenilikçilik düzeyinin cinsiyete göre farklılık göstermediğini belirlemiştir. Kartal (2018) üniversite öğrencileri olan öğretmen adayları ile gerçekleştirdiği çalışmasında, cinsiyete göre yenilikçilik düzeyinin farklılaşmadığını tespit etmiştir. Benzer sonuçların olduğu farklı çalışmalar literatürde mevcuttur (Kılıç, 2015; Kutluca, 2011; Rogers \& Wallace, 2011; Yılmaz \& Beşkaya, 2018). Bununla beraber literatürde araştırma sonuçlarını desteklemeyen çalışmaların da olduğu görülmektedir (Klecker \& Loadman, 1999; Yılmaz, Soğukçeşme, Ayhan, Tuncay, Sancar \& Deniz, 2014). Dolayısıyla, cinsiyet değisskenin bireysel yenilikçilik özelliği ile birlikte ele alındığı çalışma sonuçlarının tutarsızlığından söz etmek mümkündür. $\mathrm{Bu}$ sonucun sebebinin ise, yenilikçilik özelliğinin kendi içerisinde birçok parametreden oluştuğu ve cinsiyetten ziyade öznel farklılıkların yeniliği kabullenmede rol oynamasından kaynaklandığ1 düşünülmektedir.

Katılımcıların Dijital Okuryazarlık Ölçeğinden aldıkları toplam puan ortalaması cinsiyet değişkeni ile karşılaştırıldığında, erkek katulımcıların dijital okuryazarlık düzeylerinin kadın katılımcılara göre istatistiksel olarak daha yüksek olduğu tespit edilmiştir. Yontar (2019) öğretmen adayları ile gerçekleştirdiği çalışmasında, erkek katılımcıların dijital okuryazarlık düzeylerinin kadınlara göre daha yüksek olduğu sonucuna ulaşmıştır. Çetin (2016) tarafindan gerçekleştirilen bir başka çalışmada, erkek katılımcıların dijital okuryazarlık düzeylerinin kadınlara göre daha yüksek olduğu vurgulanmıştur. Özerbaş \& Kuralbayeva (2018) yine erkek katılımciların dijital okuryazarlık düzeyinin kadınlara göre daha yüksek olduğunu tespit etmiştir. Göldağ \& Kanat (2018) ile Horne (2007) da benzer sonuçlara ulaşmışlardır. Bu noktadan hareketle, araştırma sonuçlarının literatür tarafından desteklendiği ifade edilebilir. Erkeklerin küçük yaş gruplarından itibaren teknolojik ürünlere olan merakı, bu ürünleri kullanma isteği ve onlarla geçirdikleri zaman diliminin fazla olmasının bu sonucun ortaya çıkmasında önemli etkenler olduğu düşünülmektedir.

Araştırmada elde edilen bir başka sonuç ise, lisanslı sporculuk durumu değişkenine göre fikir önderliği alt boyutunda anlamlı bir farklılığın elde edilmesidir. Bu farklılık lisanslı sporcuların lehinedir. Bu noktadan hareketle, katılımciların lisanslı sporcu olmalarının liderlik sorumluluklarının gelişimine katkı sağladığı, düşünce ve davranışlarına özgünlük kattığı ifade edilebilir. Katılımcıların dijital okuryazarlık düzeylerinin ise lisanslı sporcu olma durumuna göre anlamlı bir farkl1lık göstermediği de belirlenmiştir.

Literatür incelendiğinde, dijital okuryazarlığın farklı değişkenler ile açıklanmaya çalışıldığı araştırmaların olduğu görülmektedir (Alvermann, 2002; Gui \& Argentin, 2011; Guzman-Simon, Garcia-Jimenez \& Lopez-Coba, 2017; Gürtekin, 2019; Greene, Seung \& Copeland, 2014; Meyers, Ericson \& Small, 2013; Pagani, Argentin, Gui \& Stanca, 2016; Park, 2011). Ancak, dijital okuryazarlı̆̆ın açıklanmasında bireysel yenilikçiliğin yordayıcı olarak kullanıldığ bir çalışmaya rastlanmamıştır. Araştırmada test edilen model sonuçları incelendiğinde, bireysel yenilikçiliğin dijital okuryazarlı̆̆ın \%37'sini açıkladığ1 görülmektedir. Dolayısı ile dijital okuryazarlığın açıklanmasında bireysel yenilikçiliğin önemli bir özellik olduğu sonucuna ulaşılmıştır. Dijital ürünlere olan merak, adaptasyon ve kullanım devamlılı̆ının aynı zamanda bireylerin yenilikçiliğe olan bakış açısı ile de ilgili olduğu ifade edilebilir. Herhangi bir kişinin yeniliklere açık olması ve olumlu bir tutum sergilemesi, nihayetinde dijital ürünlere olan ilgisini de arttırmaktadır. Bu sebeple, bireylerin yenilikçilik özelliklerinin arttırılması için etkinliklerin düzenlenmesi ve farkındalıklarının arttırılabilmesi adına çalışmaların yapılması önerilmektedir. 
Güngör, N. B., \& Kurtipek, S. (2020). Spor bilimleri fakültesi öğrencilerinin bireysel yenilikçilik düzeyinin dijital okuryazarlığa etkisinin yapısal eşitlik modeli ile incelenmesi. Journal of Human Sciences, 17(2), 756-767. doi:10.14687/jhs.v17i2.6021

\section{Kaynakça}

Alvermann, D.E. (Ed.). (2002). Adolescents and literacies in a digital world. New York: Peter Lang.

Büyüköztürk, S., Kılıç-Çakmak, E., Akgün, Ö. E., Karadeniz, Ş. \& Demirel, F. (2012). Bilimsel arastırma yöntemleri. Ankara: Pegem.

Byrne, B. M. (2010). Structural equation modeling with AMOS: Basic concepts, applications and programming. New York: Routledge.

Çakın, A. (2019). Hemşirelerin bireysel yenilikçilik düzeylerinin değı̧sime karşı tutumlarna etkisinin incelenmesi. Yüksek Lisans Tezi, Manisa Celal Bayar Üniversitesi Sağllk Bilimler Enstitüsü, Manisa.

Çekmecelioğlu, H. (2002). Bireysel, örgütsel yaratıchllk ve yaratıclhk, için iş çevresinin düzenlenmesi: Bir araştırma. Doktora Tezi, Gebze Teknik Üniversitesi Gebze İleri Teknoloji Enstitüsü, Kocaeli.

Çetin, O. (2016). Pedagojik formasyon programı ile lisans eğitimi fen bilimleri öğretmen adaylarının sayisal okur-yazarlik düzeylerinin incelenmesi. Journal of Education Faculty, 18(2), 658-685.

Çuhadar, C., Bülbül, T. \& Ilgaz, G. (2013). Öğretmen adaylanının bireysel yenilikçilik özellikleri ile teknopedagojik eğitim yeterlikleri arasındaki ilişkinin incelenmesi. İlköğretim Online, 12(3), 797807.

Demircioğlu, T., Konokman, G. Y. \& Akay, C. (2016). Eğitim fakültesi öğretim elemanlarının yenilikçilik düzeylerinin Avrupa Birliği Hayat Boyu Öğrenme Projelerine yönelik tutumlarına etkisi. Elektronik Sosyal Bilimler Dergisi, 15(59), 1120-1137.

Demirel, Y. \& Seçkin, Ö. (2008). Bilgi ve bilgi paylaşımının yenilikçilik üzerine etkileri. Cukurova Üniversitesi Sosyal Bilimler Enstitïsü Dergisi, 17(1), 189-202.

Deye, S. (2015). Promoting digital literacy among students and educators. Paper presented in National Conference of State Legislatures, Colarado.

Ertuğ, N. \& Kaya, H. (2017). Hemşirelik öğrencilerinin bireysel yenilikçilik profilleri ve yenilikçiliğin önündeki engellerin incelenmesi. Hemşirelikte Ë̆itim ve Araștrma Dergisi, 14(3), 192-197.

Gökdağ, B. \& Kanat, S. (2018). Güzel sanatlar eğitimi alan öğrencilerin dijital okuryazarlık durumları. International Journal of Social Science, 70(1), 77-92.

Gui, M. \& Argentin, G. (2011). Digital skills of internet natives: Different forms of digital literacy in a random sample of northern Italian high school students. New Media \& Society, 13(6), 963980.

Guzmán-Simón, F., García-Jiménez, E. \& López-Cobo, I. (2017). Undergraduate students' perspectives on digital competence and academic literacy in a Spanish University. Computers in Human Behavior, 74, 196-204.

Güngör, N. B. (2019). Beden eğitimi ve spor ögretmenlerinin bireysel yenilikegilike düzeyinin ögretmen profesyonelizmine olan etkisinde bilissel esnekliğin aracıllk rolï. Doktora tezi, Gazi Üniversitesi Eğitim Bilimleri Enstitüsü, Ankara.

Gürtekin, A. (2019). Üniversite ögrencilerinin boş zaman tutumlar ile sosyalleșme taktikleri ve dïital okuryazarlke düzeylerinin incelenmesi. Yüksek lisans tezi, Ağrı İbrahim Çeçen Üniversitesi Sosyal Bilimler Enstitüsü, Ağr1.

Greene, J. A., Seung, B. Y. \& Copeland, D. Z. (2014). Measuring critical components of digital literacy and their relationships with learning. Computers \& education, 76, 55-69.

Hair, J. F., Black, W. C., Babin, B. J., Anderson, R. E. \& Tatham, R. L. (1998). Multivariate data analysis. Pearson New International Edition, 5(3), 207-219.

Hirschman, E. C. (1980). Innovativeness, novelty seeking and consumer creativity. Journal of Consumer Research, 7(3), 283-295.

Horne, J. (2007). Gender differences in computerised and conventional educational tests. Journal of Computer Assisted Learning, 23(1), 47-55.

Hurt, H. T., Joseph, K. \& Cook, C. D. (1977). Scales for the measurement of innovativeness. Human Communication Research, 4, 58-65.

Karasar, N. (2017). Bilimsel araștrma yöntemi: Kavramlar ilkeler teknikler. Ankara: Nobel Akademik Yayınc1lik. 
Güngör, N. B., \& Kurtipek, S. (2020). Spor bilimleri fakültesi öğrencilerinin bireysel yenilikçilik düzeyinin dijital okuryazarlığa etkisinin yapısal eşitlik modeli ile incelenmesi. Journal of Human Sciences, 17(2), 756-767. doi:10.14687/jhs.v17i2.6021

Kartal, F. (2018). Sosyal bilgiler ögretmen adaylarmm bireysel yenilikẹilike düzeyleri ile eğitimde teknoloji kullanmmna yönelik tutumlar arasindaki ilişkilerin degerlendirilmesi. Yüksek Lisans Tezi, Kütahya Dumlupinar Üniversitesi Eğitim Bilimleri Enstitüsü, Kütahya.

Kulıç, H. (2015). İlkögrretim brans öğretmenlerinin bireysel yenilikegilik düreyleri ve yaşam boyn ögrenme eğilimleri (Deniz̧li İli örneği). Yüksek lisans tezi. Pamukkale Üniversitesi Eğitim Bilimleri Enstitüsü, Denizli.

Kilıçer, K. \& Odabaşı, H. F. (2010). Bireysel yenilikçilik ölçĕgi (BYÖ): Türkçeye uyarlama, geçerlik ve güvenirlike çalıs̆ması. Hacettepe Üniversitesi Eğitim Fakültesi Dergisi, 38, 150-164.

Kline, P. (2005). An essay guide to factor analysis. New York: Routledge.

Klecker, B. M. \& Loadman, W. E. (1999). Measuring principals' openness to change on three dimensions: Affective, cognitive and behavioral. Journal of Instructional Psychology, 26(4), 213225.

Korucu, A. T. \& Olpak, Y. Z. (2015). Öğretmen adaylarının bireysel yenilikçilik özelliklerinin farklı değişkenler açısından incelenmesi. Eğitim Teknolojisi Kuram ve Uygulama, 5(1), 111-127.

Kozan, M. \& Bulut Özek, M. (2019). Böte bölümü öğretmen adaylarının dijital okuryazarlık düzeyleri ve siber zorbalığa ilişkin duyarllıklarının incelenmesi. Furat Üniversitesi Sosyal Bilimler Dergisi, 29(1), 107-120.

Kurtipek, S. \& Güngör, N. B. (2019). Individual innovation: A research on sports manager candidattes. Journal of Education and Learning, 8(1), 224-271.

Kutluca, T. (2011). A study on computer usage and attitudes toward computers of prospective preschool teacher. International Journal on New Trends in Education and Their Implications, 2(1), 1 14.

Leech, N. L., Barrett, K. C. \& Morgan, G. A. (2005). SPSS for intermediate statistics: Use and interpretation. Psychology Press.

Martin, A. (2005). DigEuLit-a European framework for digital literacy: a progress report. Journal of eLiteracy, 2(2), 130-136.

Meydan, C. H. \& Şeşen, H. (2011). Yapısal eşitlik modellemesi AMOS uygulamalar. Ankara: Detay Yayincilik.

Meyers, E. M., Ericson, I. \& Small, R. V. (2013). Digital literacy and informal learning environments: An introduction. Learning, Media and Technology, 38(4), 355-367.

$\mathrm{Ng}, \mathrm{W}$. (2012). Can we teach digital natives digital literacy? Computers \& Education, 59, 1065-1078.

Onursoy, S. (2018). Üniversite gençliğinin dijital okuryazarlık düzeyleri: Anadolu Üniversitesi öğrencileri üzerine bir araştırma. Gümüshane Üniversitesi İletișim Fakültesi Elektronik Dergisi, 6(2), 989-1013.

Özerbaş, M. \& Kuralbayeva, A. (2018). Türkiye ve Kazakistan öğretmen adaylarının dijital okuryazarlık düzeylerinin değerlendirilmesi. Muğla Sıtkı Koçman Üniversitesi Eğitim Fakültesi Dergisi, 5(1), 16-25.

Üstündağ, M. T., Güneş, E., \& Bahçivan, E. (2017). Dijital okuryazarlık ölçeğinin türkçeye uyarlanması ve fen bilgisi ögrretmen adaylarının dijital okuryazarlık durumları. Journal of Education and Future, 12, 19-29.

Pagani, L., Argentin, G., Gui, M. \& Stanca, L. (2016). The impact of digital skills on educational outcomes: evidence from performance tests. Educational studies, 42(2), 137-162.

Park, Y. J. (2013). Digital literacy and privacy behavior online. Communication Research, 40(2), 215-236.

Rogers, E. M., Medina, U. E., Rivera, M. A. \& Widey, C.L. (2005). Complex adaptive systems and the diffusion of innovations. The Innovation Journal: The Public Sector Innovation Journal, 10(3), 126.

Rogers, R. K. \& Wallace, J. D. (2011). Predictors of technology integration in education: A study of anxiety and innovativeness in teacher preparation. Journal of Literacy and Technology, 12(2), 2861. 
Güngör, N. B., \& Kurtipek, S. (2020). Spor bilimleri fakültesi öğrencilerinin bireysel yenilikçilik düzeyinin dijital okuryazarlığa etkisinin yapısal eşitlik modeli ile incelenmesi. Journal of Human Sciences, 17(2), 756-767. doi:10.14687/jhs.v17i2.6021

Safa, B. S. (2019). Sinf ögretmenlerinin eğitim teknolojileri kullanım düzeylerinin bireysel yenilikęilik özellikleri açısindan incelenmesi. Yüksek Lisans Tezi, Adnan Menderes Üniversitesi Sosyal Bilimler Enstitüsü, Aydın.

Schermelleh-Engel, K., Moosbrugger, H. \& Müller, H. (2003). Evaluating the fit of structural equation models: Tests of significance and descriptive goodness-of-fit measures. Methods of Psychological Research Online, 8(2), 23-74.

Şahin, F. (2016). Öğretmen adaylarmm bilișim teknolojileri kabul dü̈eyleri ile bireysel yenilikçilik düreyleri arasındaki ilişkinin incelenmesi. Yüksek lisans tezi, Anadolu Üniversitesi Eğitim Bilimleri Enstitüsü, Eskişehir.

Şeker, H., Deniz, S. \& Görgen, İ. (2004). Öğretmen yeterlikleri ölçeği. Milli Eğitim Dergisi, 164, 105118.

Tabachnick, B. G. \& Fidell, L. S. (2007). Experimental designs using ANOVA. Belmont, CA: Thomson/Brooks/Cole.

Yalçın, İ. E. \& Yelken, Y. T. (2011, Ekim). İlkögrretim ögretmen adaylarmm yenilikegilik düzeyleri. I. Uluslararası Eğitim Programları ve Öğretim Kongresi'nde sunulmuş bildiri. Anadolu Üniversitesi, Eskişehir.

Yılmaz, F., Soğukçeşme, G., Ayhan, N., Tuncay, S., Sancar, S. \& Deniz, Y. M. (2014). İlköğretim bölümü öğretmen adaylarının mesleki yenilikçilik eğilimlerinin çeşitli değişkenler açısından incelenmesi. Mustafa Kemal Üniversitesi Sosyal Bilimler Enstitüsü Dergisi, 11(27), 259-276.

Yılmaz, R. \& Beşkaya, Y. M. (2018). Eğitim yöneticilerinin yaşam boyu öğrenme eğilimleri ile bireysel yenilikçilik düzeylerinin incelenmesi. Ankara Üniversitesi Eğitim Bilimleri Fakültesi Dergisi, 51 (1), 159-181.

Yontar, A. (2019). Öğretmen adaylarının dijital okuryazarlık düzeyleri. Ana Dili Eğitimi Dergisi, 7(4), 815-824.

\section{Extended English Summary}

Introduction: Today, the rapid development of technology, differentiation of our habits in a short period of time and the ease of use of new products also affect the perspective of innovations. Rogers, Medina, Rivera \& Widey (2005) expressed the need for a new application or object to exist by the individual or society when defining innovation. Innovation, on the other hand, can be expressed as the acceptance of any innovation more quickly than other people (Rogers \& Wallace, 2011). The person who has an innovative perspective aims to think about the problems and provide solutions to them. Nevertheless, it looks for the invisible behind the current situation by giving importance to establishing new and different relationships (Çekmecelioğlu, 2002). One of the areas where individuals' innovative profiles can be seen is the digital world. The tools and equipment of the digital world are being updated day by day. A technology that can be described as new today can be seen as old tomorrow. Keeping up with this development is important for individuals. Digital literacy means a tendency to use innovative digital materials and their associated stakeholders. The ability to use these materials also provides an efficient environment for production. Digital literate individuals are people who can access correct information, have the ability to synthesize by using knowledgeable, and present this information in digital environments (Kozan \& Bulut Özek, 2019). When the literature is analyzed, there is no study about the predictive effect of individual innovation on digital literacy. Therefore, this study is important in terms of contributing to the literature and determining the digital literacy levels of the Faculty of Sport Sciences students. The aim of this study is to reveal the effect of individual innovation level of students of the Faculty of Sport Sciences on digital literacy. 
Güngör, N. B., \& Kurtipek, S. (2020). Spor bilimleri fakültesi öğrencilerinin bireysel yenilikçilik düzeyinin dijital okuryazarlığa etkisinin yapısal eşitlik modeli ile incelenmesi. Journal of Human Sciences, 17(2), 756-767. doi:10.14687/jhs.v17i2.6021

Methodology: Relational screening model was used in the research. This model; It is used to determine the relationship between two or more variables and to obtain clues about cause and effect (Karasar, 2017). As a result of the literature review, the model of the research was established based on the existing variables. The test of the theoretical model was tested using the structural equation model. The study group of the research; It consists of 205 participants who continue their education in a higher education institution in Ankara that provides undergraduate sports education in the 20192020 academic year. Data collection tools; It is "Individual Innovation Scale" and "Digital Literacy Scale". With the determination of the suitability of the scales for factor analysis, the theoretical model created in the research was tested by establishing a structural equation model. However, T-test was used to compare the average scores of the participants according to gender and licensed athletic status variables.

Findings and Discussion: The results of the research show that the level of individual innovation of the participants is above average and they are in the "questioner" category. Therefore, it can be stated that the participants examined the alternatives before accepting anything, took a careful attitude towards accepting innovations, did not accept the innovations in a short time and did not like to take risks in this regard. When the total score obtained from the Digital Literacy Scale is examined, it can be stated that the participants' digital literacy level is above average. It can be said that participants have the ability to easily learn new technologies, their level of knowledge about different technologies, and the ability to solve technical problems they may encounter with the technologies they use. Compared to the gender variable, the total score of the participants received from the Digital Literacy Scale was found to be statistically higher than that of the male participants. However, it was concluded that the level of individual innovation does not differ by gender. Another result obtained in the research is to obtain a meaningful difference in the opinion leadership sub-dimension according to the licensed athletic status variable. This difference is in favor of licensed athletes. From this point of view, it can be stated that being a licensed athlete contributes to the development of leadership responsibilities and adds originality to their thoughts and behaviors. It was also determined that the digital literacy levels of the participants did not differ significantly according to the status of being a licensed athlete. When the model results tested in the research are examined, it is seen that individual innovation explains $37 \%$ of digital literacy. Therefore, it was concluded that individual innovation is an important feature in explaining digital literacy. It can be stated that the curiosity, adaptation and continuity of digital products are also related to individuals' perspective on innovation. The fact that anyone is open to innovations and has a positive attitude eventually increases their interest in digital products. For this reason, it is recommended to conduct activities in order to increase the awareness of individuals and to organize activities and increase their awareness. 